\title{
SHEA Newsletter
}

Edited by Robert A. Weinstein, MD

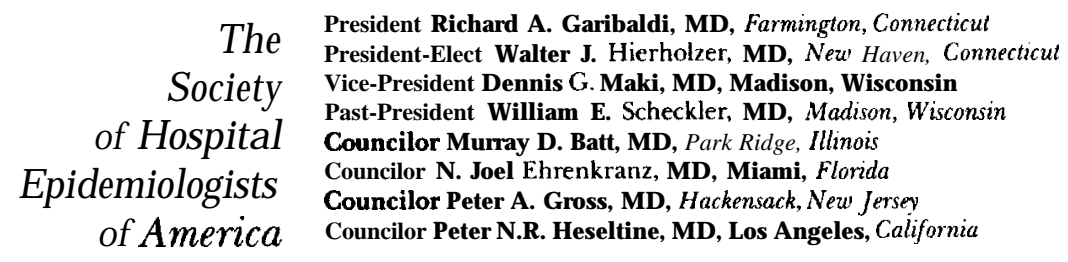

\section{SHEA Board Meeting}

The SHEA board met on October 23 , 1988. Timothy Townsend, MD, secretary, reported that 59 new members have joined SHEA since January 1 , 1988, bringing our membership to approximately 500 . He also reported the recent election results: $C$. Glen Mayhall, MD, vice-president; Bruce Hamory, MD, treasurer; and Jeffrey Band, MD and Dennis Schaberg, MD, councillors.

John Burke, MD, treasurer, reported that our income, primarily $\$ 23,000$ in dues, has exceeded our expenses and that the Society financial balance is $\$ 57,000$. He noted that our net worth has been stable for the past two to three years, despite a marked decrease in pharmaceutical company support.

Richard Garibaldi, MD, president, reflected on the accomplishments of 1988 , which include an increase in membership; the SHEA/CDC training course (see November Newsletter) for fellows and new chairs of infection control committees (which despite being held in August in Atlanta was well attended and quite oversubscribed); plans for a second annual SHEA/CDC course which will be codirected by Allen Kaiser, MD and Donald Goldmann, MD and will immediately precede the CDC's April 1989 Epidemic Intelligence Service Conference; the formal association of SHEA with the-journal, Infection Con- trol and Hospital Epidemiology; and an outreach to infectious disease fellows that included the training course and specific mailings to encourage fellows to become associate members of SHEA.

Dr. Garibaldi stated that plans were well underway for the March 1989 SHEA national conference, "N ew Challenges and Controversies" (see November $\mathrm{N}$ ewsletter and the program in the center of this issue). SHEA members are urged to submit abstracts for the poster sessions of this meeting.

Dr. Garibaldi further noted that the Severity of IIIness Working Group published its findings in the journal (see July issue) and that the SHEA/ APIC task force is currently reviewing the issue of the HIV-infected health care worker (see below).

Finally, Dr. Garibaldi reviewed the deliberations of the SHEA presidents' strategic planning session (see summary below).

\section{Strategic Long-Term Planning}

In early October, Dr. Garibaldi convened a meeting of past SHEA presidents and the president-elect to formulate long-term plans.

The group agreed to make the SHEA/CDC training course (see above) an annual event. This offering will be directed by a subcommittee of the Educational Activities Committee. 